\section{Effectiveness of Combination of Dentin and Enamel Layers on the Masking Ability of Porcelain}

Noéli Boscato ${ }^{1}$, Fernando Gabriel Hauschild², Marina da Rosa Kaizer ${ }^{1}$, Rafael Ratto de Moraes ${ }^{1}$
'Graduate Program in Dentistry, UFPel - Universidade Federal de Pelotas, Pelotas, RS, Brazil ${ }^{2}$ Private Practice, Pelotas, RS, Brazil

Correspondence: Prof. Rafael Ratto de Moraes, Rua Gonçalves Chaves 457, room 505, 96015-560, Pelotas, RS, Brasil. Tel: +55-53-3225-6741. Ext.: 135. e-mailmoraesrr@gmail.com

\begin{abstract}
This study evaluated the masking ability of different porcelain thicknesses and combination of enamel and/or dentin porcelain layers over simulated background dental substrates with higher (A2) and lower (C4) color values. Combination of the enamel (E) and dentin (D) monolayer porcelain disks with different thicknesses $(0.5 \mathrm{~mm}, 0.8 \mathrm{~mm}$, and $1 \mathrm{~mm})$ resulted in the following bilayer groups ( $n=10)$ : D1E1, D1E0.8; D1E0.5; D0.8E0.8; D0.8E0.5, and D0.5E0.5. CIELAB color coordinates were measured with a spectrophotometer. The translucency parameter of mono and bilayer specimens and the masking ability estimated by color variation $\left(\Delta E_{\mathrm{ab}}^{*}\right)$ of bilayer specimens over simulated dental substrates were evaluated. Linear regression analysis was used to investigate the relationships translucency parameter $\times \Delta E^{*}$, translucency parameter $\times$ porcelain thickness, and $\Delta E^{*} \times$ porcelain thickness. Data were analyzed statistically $(\alpha=0.05)$. Thinner porcelain disks were associated with higher translucency. Porcelain monolayers were considerably more translucent than bilayers (enamel + dentin). Dentin porcelain was less translucent than enamel porcelain with same thickness. $\Delta E^{*}$ was always lower when measured over A2 background. Higher $\Delta E^{*}$ was observed for the $\mathrm{C} 4$ background, indicating poorer masking ability. Increased $\Delta E^{*}$ was significantly associated with increased translucency for both backgrounds. Decreased translucency and $\Delta E^{*}$ were associated with increased total porcelain thickness or increased dentin thickness for both backgrounds. In conclusion, increased porcelain thickness (particularly increased dentin layer) and increased porcelain opacity resulted in better masking ability of the dental backgrounds.
\end{abstract}

Key Words: aesthetics, color, ceramics, laminate veneers, translucency.

\section{Introduction}

Dental restorations by using porcelain laminate veneers favor the matching of the optical properties of natural teeth to obtain long-term good clinical results (1). The thin structure of porcelain laminate veneers allows light to be reflected and scattered from the underlying enamel and dentin (2). Therefore, the color of the abutment tooth may influence the final color of porcelain laminate veneer restorations as the optical properties and luminosity of the translucent porcelain are altered by background (3).

The aesthetic performance of porcelain laminate veneers is influenced by several characteristics of the dental substrate and restorative materials. Factors such as porcelain composition, translucency, and thickness, as well the color of the luting cement and underlying tooth abutment, play a synergistic role in the resulting optical qualities (4-14). Appropriate knowledge and management of color and lighting effects may render restorations with the appearance of natural teeth, as the optical properties of porcelain laminate veneers are determined by light interaction with different materials (1).

In clinical situations when discolored abutment teeth need restorations, porcelain laminate veneers should be able to mask the underlying color for the restoration to attain adequate aesthetic properties. This might be challenging considering the thin structure and translucent characteristic of the porcelain used to prepare the veneers. The masking ability of porcelain laminate veneers over discolored abutment teeth might be improved by using thicker porcelain layers and/or increasing the removal of dental structure (15-18). This assumption is based on clinical practice only, as there is no consensus in the literature regarding the ideal porcelain thickness for the various porcelain systems commercially available or the optimal amount of tooth structure removal to place porcelain laminate veneers with the best masking ability $(15,19-23)$.

The aim of this study was to evaluate in vitro the masking ability and optical effects of different enamel and/or dentin porcelain thicknesses over simulated dental substrates (backgrounds) with higher (A2) and lower (C4) color values. The hypotheses tested were that (i) increased porcelain thickness and (ii) increased porcelain opacity would result in better masking ability.

\section{Material and Methods \\ Preparation of Porcelain Veneers}

Enamel and dentin porcelains (shade A2) were tested (VM7; Vita Zahnfabrik, Bad Sackingen, Germany). Cylindrical 
porcelain green bodies ( $15 \mathrm{~mm}$ thick, $7 \mathrm{~mm}$ diameter) were made by mixing approximately $1 \mathrm{~g}$ porcelain powder with $0.5 \mathrm{~mL}$ distilled water. The green body was pressed in a pneumatic press and sintered under vacuum in a ceramic furnace according to the manufacturers instructions: 500 ${ }^{\circ} \mathrm{C}$ initial temperature, 6 min drying time, $55^{\circ} \mathrm{C} /$ min heating rate, $910^{\circ} \mathrm{C}$ final temperature. Considering approximately $10 \%$ shrinkage of the porcelain, the cylindrical specimens had final dimensions of $13.5 \mathrm{~mm} \times 6.3 \mathrm{~mm}$. The sintered porcelain cylinders were sectioned into thickness of 0.5 $\mathrm{mm}, 0.8 \mathrm{~mm}$ or $1 \mathrm{~mm}$ ( $\mathrm{n}=10$ for each thickness) by using a low-speed diamond saw under constant water-cooling. All disks were finished flat on both sides in an automatic polisher with 1200-grit SiC papers under water-cooling. A digital caliper was used to measure the final thicknesses, and the specimens were ultrasonically cleaned in distilled water for $10 \mathrm{~min}$.

\section{Preparation of Simulated Tooth Substrates}

Two dentin porcelain disks were fabricated in order to simulate background tooth substrates with lower (C4) and higher (A2) color values. The disks had similar color parameters except for the difference in value. Each disk was prepared by mixing approximately $0.5 \mathrm{~g}$ porcelain powder with $0.25 \mathrm{~mL}$ distilled water. The lower-value disk was obtained by adding $0.1 \mathrm{~g} \mathrm{SnO}_{2}$ pigment to the porcelain before fabrication of the green body. The disks had a 10 $\mathrm{mm}$ diameter and $2 \mathrm{~mm}$ thickness and were finished flat on both sides, as described for the porcelain veneers.

\section{Groups}

The porcelain laminate veneers were evaluated in two conditions: monolayers, monolithic disks of enamel porcelain or dentin porcelain with different thicknesses; and bilayers, dentin porcelain disks covered with enamel porcelain disks of different thicknesses, as shown in Table 1. The dentin layer was always thicker than or had the same thickness as the enamel layer. The enamel porcelain was not sintered to the dentin porcelain; the covering enamel layer was only positioned over the dentin for the color analysis.

\section{Measurement of CIELAB Color Coordinates}

The CIELAB color coordinates of each dentin and enamel

Table 1. Enamel and dentin porcelain combinations tested $(n=10)$

\begin{tabular}{lccc}
\hline & $\begin{array}{c}\text { Enamel } \\
1 \mathrm{~mm}\end{array}$ & $\begin{array}{c}\text { Enamel } \\
0.8 \mathrm{~mm}\end{array}$ & $\begin{array}{c}\text { Enamel } \\
0.5 \mathrm{~mm}\end{array}$ \\
\hline Dentin $1 \mathrm{~mm}$ & D1E1 & D1E0.8 & D1E0.5 \\
Dentin $0.8 \mathrm{~mm}$ & - & D.8E0.8 & D0.8E0.5 \\
Dentin $0.5 \mathrm{~mm}$ & - & - & D0.5E0.5 \\
\hline
\end{tabular}

monolayer, as well as all bilayer specimens were measured with a spectrophotometer (Vita Easyshade; Vita Zahnfabrik). Measurements were performed by using glycerin as a coupling medium between the dentin and enamel disks and between the dentin disks and the simulated tooth substrate/ background. Glycerin presents a refraction index similar to porcelain, minimizing the light refraction that occurs when the light beam crosses substrates with different refractive indices as air and porcelain (24). The monolayer and bilayer specimens were evaluated on a white background $\left(L^{*}=93.1\right.$; $\left.a^{*}=1.3 ; b^{*}=5.3\right)$ and a black background $\left(L^{*}=27.9 ; a^{*}=0.0\right.$; $b^{*}=0.0$ ). The bilayer specimens were also evaluated with the simulated tooth substrates with lower value and higher value as backgrounds: $C 4\left(L^{*}=54.9 ; a^{*}=2.9 ; b^{*}=25.7\right)$ and A2 $\left(L^{*}=79.2 ; a^{*}=2.5 ; b^{*}=24.2\right)$.

\section{Evaluation of Porcelain Translucency Parameter}

The translucency of monolayer and bilayer specimens was determined by calculation of the translucency parameter (TP) according to the following equation (25):

$$
\left.\mathrm{TP}=\left(L{ }_{\mathrm{W}}-L{ }_{\mathrm{B}}\right)^{2}+\left(a{ }_{\mathrm{W}}-a^{*}{ }_{\mathrm{B}}\right)^{2}+\left(b{ }_{\mathrm{W}}-b^{*}{ }_{\mathrm{B}}\right)^{2}\right)^{1 / 2}
$$

(Eq. 1), where subscript $W$ and subscript $B$ refer to the color coordinates measured on the white and black backgrounds.

\section{Evaluation of Masking Ability of Simulated Tooth Substrates}

The masking ability of the bilayer specimens was estimated by the color variation $\left(\Delta E^{*}\right)$ of the porcelain laminate veneer measured over the simulated tooth substrates with distinct values ( $\mathrm{C} 4$ and $\mathrm{A} 2$ ) and over the white background according to the following equation (25):

$$
\left.\Delta E^{*}{ }_{\mathrm{ab}}=\left(L *_{1}-L^{*}{ }_{\mathrm{W}}\right)^{2}+\left(a{ }_{1}-a{ }_{\mathrm{W}}\right)^{2}+\left(b{ }_{1}-b{ }^{*}{ }_{\mathrm{W}}\right)^{2}\right)^{1 / 2}
$$

(Eq. 2), where subscript 1 refers to the color coordinates measured over the higher-value (A2) or lower-value (C4) backgrounds, and subscript $W$ refers to the color coordinates measured over the white background.

\section{Statistical Analysis}

Translucency parameter and $\Delta E^{*}$ data were homoscedastic and were analyzed by one-way analysis of variance. All pairwise multiple comparisons were performed by the Student-Newman-Keuls method. Linear regression analysis was used to investigate the relationships between the following pairs of variables: translucency parameter $x \Delta E^{*}$, translucency parameter $\times$ porcelain thickness, and $\Delta E^{*} \times$ porcelain thickness. The significance level was set at $\alpha=0.05$. Statistical analyses were carried out using software (SigmaPlot 11.0; Systat Software Inc., San Jose, CA, USA). 


\section{Results}

\section{Translucency of Monolayers and Bilayers}

Results for translucency parameter of the monolayer and bilayer porcelain conditions are presented in Figure 1. For both dentin and enamel monolayers, lower porcelain thicknesses led to higher translucency. Dentin veneers always had lower translucency parameter than enamel veneers with the same thickness. For the bilayers, a general increase in translucency parameter was observed with decreased porcelain thickness, with a thicker dentin layer determining a more opaque bilayer. The monolayers were considerably more translucent than the bilayers, among which the most opaque monolayer (D1) was the only group statistically similar to the most translucent bilayer (D0.5E0.5).

\section{Masking Ability of the Bilayer Specimens}

Results for masking ability (estimated by $\Delta E^{*}$ results) of the bilayer groups over the simulated tooth substrates are presented in Figure 2. The $\Delta E^{*}$ was higher (the masking ability was lower) when the specimens were tested over the lower-value background. The final thickness of the specimens only had a significant effect on color variation

final colo color of the veneers. The lower-value background had a greater influence on the final veneer color than the higher-value background. The thinner bilayer group (D0.5E0.5) had almost 40\% less masking ability when measured over the lower-value background compared to the higher-value background.

\section{Results for CIE $L^{*}, a^{*}$ and $b^{*}$}

Figure 3 shows the results for the individual CIELAB color coordinates for all monolayer and bilayer porcelains

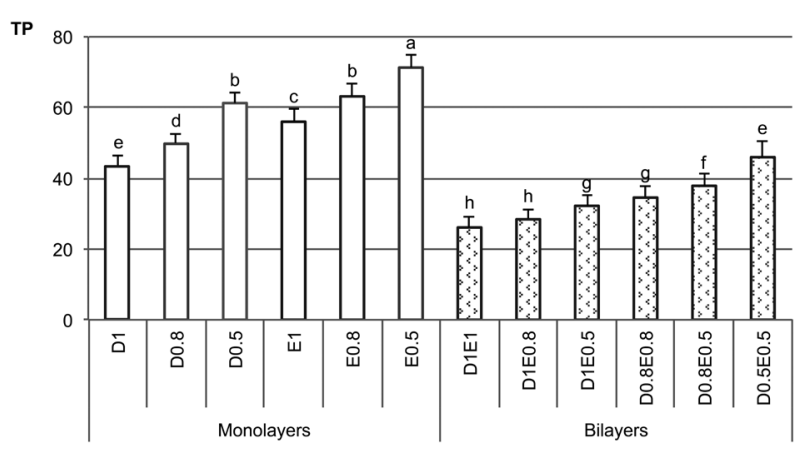

Figure 1. Translucency parameter (TP) for monolayer and bilayer groups (bars are means \pm standard deviations). Distinct letters indicate statistically significant differences $(\mathrm{p}<0.05)$. according to the thickness of each porcelain layer (enamel and dentin). The main differences were observed in $b^{*}$ values. For the monolayers, a lower porcelain thickness generally determined increased $L^{*}$ for enamel disks and decreased $L^{*}$ for dentin disks, while no appreciable differences in $a^{*}$ were observed. For $b^{*}$, the difference between enamel and dentin porcelain was appreciable; dentin veneers showed lower $b^{*}$ with increased porcelain thicknesses. Bilayers with $0.5 \mathrm{~mm}$ of enamel porcelain had lower $L^{*}$ values, and no detectable differences in $a^{*}$ were observed. Increased $b^{*}$ values were observed with decreased enamel thickness and increased dentin thickness.

\section{Linear Regression Analyses}

Linear regression plots of $\Delta E^{*} x$ translucency parameter for the bilayers analyzed over the higher-value and lowervalue simulated tooth backgrounds are shown in Figure 4. $\Delta E^{*}$ values were linearly associated with translucency parameter values for both backgrounds $\left(R^{2} \leq 0.871\right.$; $\mathrm{p} \leq 0.007)$. The association between $\Delta E^{*}$ and translucency parameter was stronger for the lower-value background $\left(R^{2}=0.994\right)$. Figure 5 shows the results for the linear regression analyses of translucency parameter, $\Delta E^{*}$ for the higher-value background, or $\Delta E^{*}$ for the lower-value background with the thickness of the bilayer porcelain veneer (total porcelain thickness, dentin porcelain thickness, or enamel porcelain thickness). Decreased translucency parameter and $\Delta E^{*}$ values were associated with increased total porcelain thickness $\left(R^{2} \leq 0.876 ; p \leq 0.006\right)$ or increased dentin porcelain thickness $\left(R^{2} \leq 0.690 ; p \leq 0.041\right)$, irrespective of the background color value. The enamel porcelain thickness was not associated with changes in translucency parameter or $\Delta E^{*}(p \geq 0.061)$.

\section{Discussion}

The two hypotheses tested were accepted since both porcelain thickness and opacity were associated with a

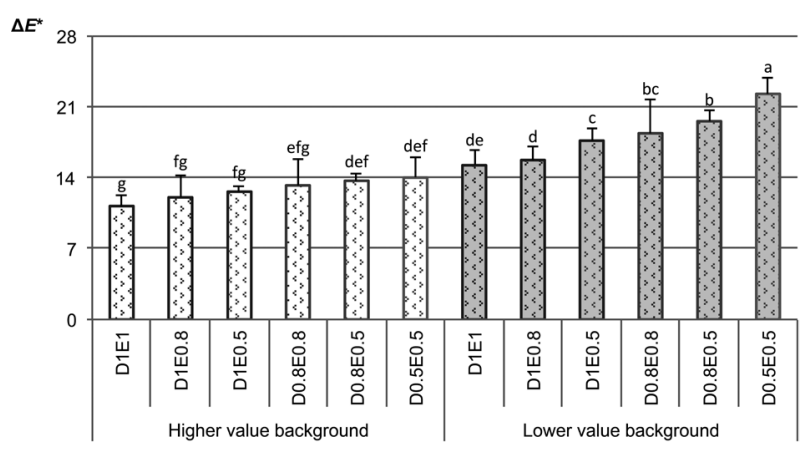

Figure 2. Masking ability (estimated by $\Delta E^{*}$ results) of porcelain bilayer groups tested over higher-value (A2) and lower-value (C4) simulated tooth substrates (bars are means + standard deviations). Distinct letters indicate statistically significant differences $(\mathrm{p}<0.05)$. 
better masking ability of the simulated tooth substrates. The aesthetic outcome of porcelain laminate veneers is generally accounted as the combined effect of the dental background color with the thickness of the porcelain restoration (enamel and dentin porcelain layers) and the optical properties of porcelain (4-7). This study simulated a clinical situation in which porcelain laminate veneer restorations are placed over dental substrates of darker or lighter colors. Proper measurement of the in vitro optical qualities of multilayer configurations that simulate clinical restorative conditions is quite challenging. Therefore, several variables that could interfere with the final color and translucency of the porcelain laminate veneers were controlled in this study, such as ambient light conditions (22), ceramic shade (13), ceramic composition $(20,22,29)$, ceramic glazing $(8,16)$, and ceramic firing conditions (16).

Translucency can be defined as a partial opacity or as a state between total transparency and total opacity and occurs when an electromagnetic light beam crosses a material and is partly scattered, reflected, absorbed, and transmitted through it. The translucency of materials may define their potential to mask the color of a defined background (9). In the present study, it was observed that a combination of enamel and dentin porcelain layers resulted in lower translucency parameter, indicating a better masking ability for the bilayers compared to the monolayers. The least translucent monolayer (D1), for instance, was equivalent to the most translucent bilayer (D0.5E0.5), and both were $1 \mathrm{~mm}$ in thickness. These findings can be associated with the diverse optical phenomena that photons may undergo when a light beam transfers from one porcelain layer to another, with a wavelength dependent reflection and the transmission coefficient of the scattering layers dictating the process (2). Therefore, when it comes
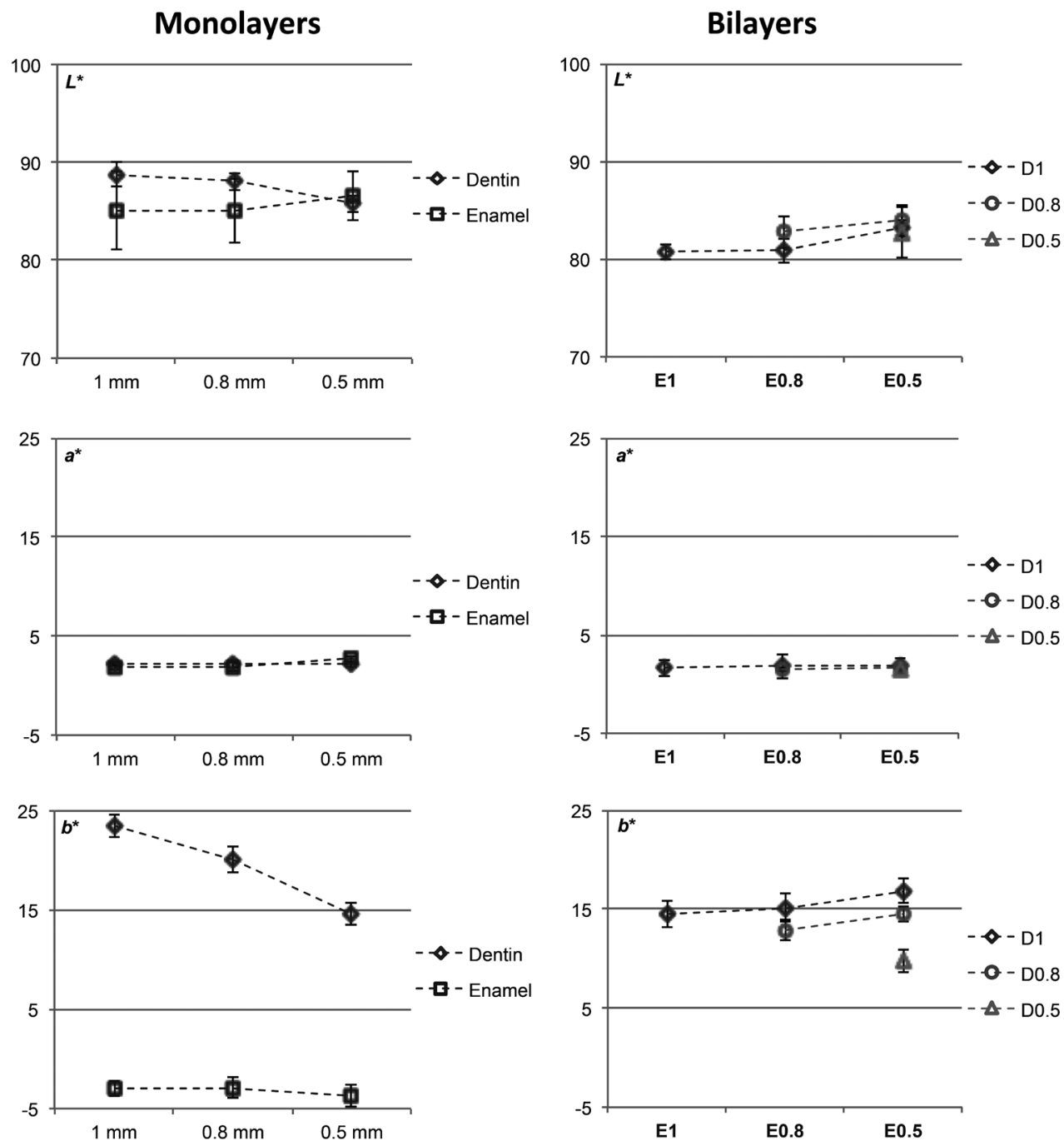

Figure 3. CIELAB color coordinates for monolayers and bilayers according to thickness of each porcelain layer (enamel and dentin). Main differences were observed in $b^{*}$ values. For monolayers, difference in $b^{*}$ between enamel and dentin is appreciable. For bilayers, increased $b^{*}$ values were observed for decreased enamel thickness and increased dentin thickness. 
to generating more translucent restorations, the use of a single porcelain layer seems preferable provided that the background dental structure is not of a low-value color.

Dentin porcelain always had a lower translucency parameter than enamel porcelain when their thickness was the same. This finding implies that a thicker dentin layer generates better masking potential for porcelain restorations, probably because the effect of dentin chromaticity in the final tooth color is much greater than enamel chromaticity (2). A recent study (2) showed that placing an enamel slice on top of a dentin-analogue background increases its lightness, giving an external appearance lighter than the underlying substrate. Although the porcelain enamel is important to the final aesthetic qualities of laminate veneers, the thickness of the porcelain enamel should be planned with caution, particularly when the tooth background has a low color value. The masking ability of veneers was also largely dictated by the total thickness of the porcelain restoration. Thicker veneers generated better masking ability, probably due to a combined effect of lower translucency and higher light diffusion. Previous studies revealed that the translucency of the restorative material is, among other factors, affected by their thickness $(9-11,17)$. It has also been reported that the light transmittance through porcelain laminate veneers is more influenced by the restoration thickness than by their color (22).

When the porcelain specimens were evaluated over the lower-value background, large variation in $\Delta E^{*}$ and
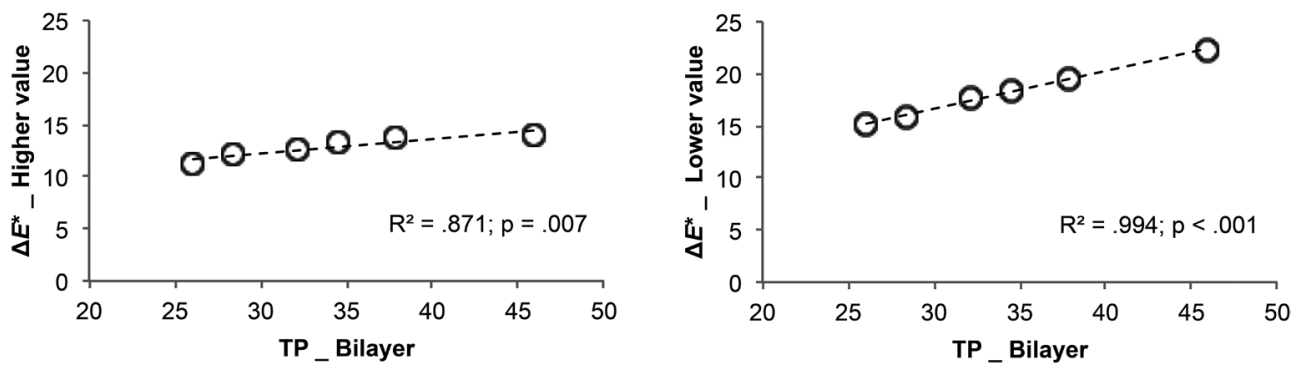

Figure 4. Association of color variation $\left(\Delta E^{*}\right)$ and translucency parameter (TP) for porcelain bilayers analyzed over higher-value (A2) and lowervalue (C4) simulated tooth backgrounds. Coefficients of linear regression $\left(\mathrm{R}^{2}\right)$ and their respective $\mathrm{p}$ values are displayed for each condition.
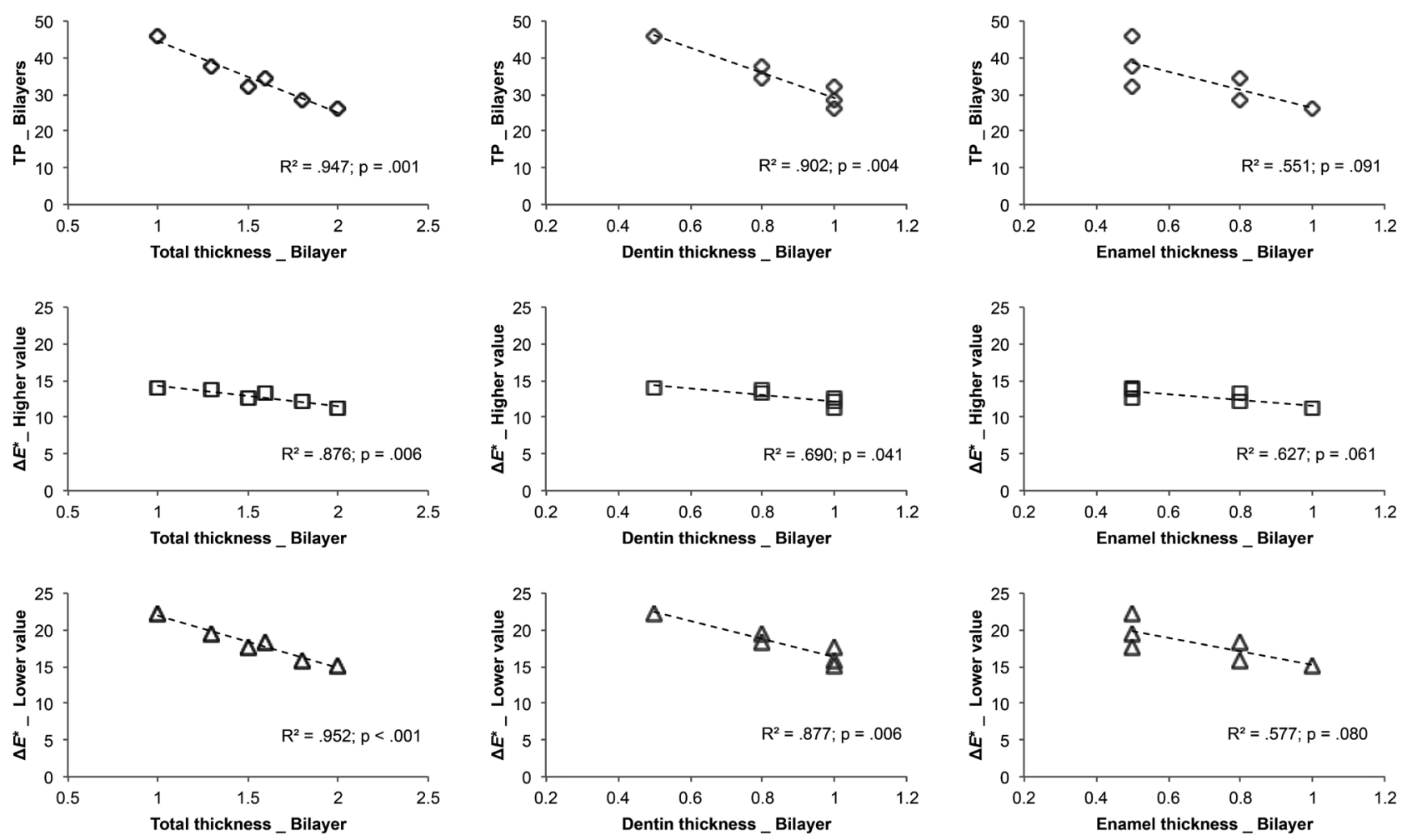

Figure 5. Association of translucency parameter (TP) and color variation ( $\left.\Delta E^{*}\right)$ for higher-value background (A2), or $\Delta E^{*}$ for lower-value background (C4) with thickness of porcelain veneer. Coefficients of linear regression $\left(\mathrm{R}^{2}\right)$ and their respective $\mathrm{p}$ values are displayed for each condition. 
translucency parameter was observed even for discreet alterations in total porcelain thickness. The thinner bilayer group had almost $40 \%$ less masking ability over the lowervalue background when compared to the higher-value background, for instance. The masking ability over the simulated darkened dental substrate (lower color value) was generally low. $\Delta E^{*}$ average values up to 17.3 were detected for the lower-value background, whereas the $\Delta E^{*}$ average values for the higher-value background were all below 14. The difference in mean $\Delta E^{*}$ between the lower and higher-value backgrounds was $\sim 3.3$, which is considered visually perceptible and clinically relevant (12). In fact, the porcelain tested presents a large content of vitreous phase, which gives it high translucency due to reduced internal light scattering by the crystalline content (21). When better masking ability is needed, a thicker dentin layer should be used due to its more opaque characteristic, although the combination with a covering enamel layer also interferes with light scattering and improves masking. However, even the thicker bilayers or the bilayers with higher opacity did not have proper ability to mask the $\mathrm{C} 4$ value background.

When darkened teeth require aesthetic restorative treatments, the combination of different thicknesses of enamel and dentin porcelain layers and selection of a ceramic system with enough ability to mask the underlying substrate is advised. It seems reasonable that other treatment options should be elected, such as the use of ceramic crowns fabricated from more opaque ceramics for the framework, particularly ceramics with higher content of crystalline phase.

\section{Resumo}

Este estudo avaliou a capacidade de mascaramento de diferentes espessuras de porcelana e a combinação de camadas de porcelana de esmalte e/ou de dentina sobre substratos dentais simulados de fundo com cores de maior (A2) e menor (C4) valor. Combinação de discos de porcelana em monocamadas de esmalte (E) e dentina (D) com diferentes espessuras $(0,5$ $\mathrm{mm}, 0,8 \mathrm{~mm}$ e $1 \mathrm{~mm}$ ) resultou nos seguintes grupos bicamadas ( $\mathrm{n}=10)$ : D1E1, D1E0,8; D1E0,5; D0,8E0,8; D0,8E0,5 e D0,5E0,5. Coordenadas de cor CIELAB foram mensuradas com um espectrofotômetro. 0 parâmetro de translucidez de espécimes mono e bicamadas e a capacidade de mascaramento estimada pela variação de $\operatorname{cor}\left(\Delta E_{\mathrm{ab}}^{*}\right)$ dos espécimes bicamadas sobre os substratos dentais simulados foram avaliados. Análise de regressão linear foi utilizada para investigar as relações parâmetro de translucidez $\times \Delta E^{*}$, parâmetro de translucidez $\mathrm{x}$ espessura da porcelana, e $\Delta E^{*} \mathrm{x}$ espessura da porcelana. Os dados foram analisados estatisticamente $(\alpha=0,05)$. Discos de porcelana mais finos foram associados a maior translucidez. Monocamadas de porcelana foram consideravelmente mais translúcidas que bicamadas (esmalte + dentina). Porcelana de dentina foi menos translúcida que porcelana de esmalte com mesma espessura. $\Delta E^{*}$ foi sempre menor quando mensurado sobre fundo $\mathrm{A} 2$. Maior $\Delta E^{*}$ foi observado para o fundo $\mathrm{C} 4$, indicando pior capacidade de mascaramento. Maior $\Delta E^{*}$ foi significativamente associado à maior translucidez para ambos fundos. Menor translucidez e $\Delta E^{*}$ foram associados ao aumento da espessura total da porcelana ou aumento da espessura de dentina para ambos fundos. Em conclusão, aumento da espessura da porcelana (particularmente aumento da camada de dentina) e aumento da opacidade da porcelana resultaram em melhor capacidade de mascaramento dos fundos dentários.

\section{References}

1. Beier US, Kapferer I, Burtscher D, Dumfahrt H. Clinical performance of porcelain laminate veneers for up to 20 years. Int J Prosthodont 2012;25:79-85.

2. Battersby PD, Battersby SJ. Measurements and modelling of the influence of dentine colour and enamel on tooth colour. J Dent 2015:43:373-381.

3. Chaiyabutr Y, Kois JC, Lebeau D, Nunokawa G. Effect of abutment tooth color, cement color, and ceramic thickness on the resulting optical color of a CAD/CAM glass-ceramic lithium disilicate-reinforced crown. J Prosthet Dent 2011;105:83-90.

4. Li $\mathrm{Q}, \mathrm{Yu}$ H, Wang YN. Spectrophotometric evaluation of the optical influence of core build-up composites on all-ceramic materials. Dent Mater 2009;25:158-165.

5. Christensen GJ. Facing the challenges of ceramic veneers. J Am Dent Assoc 2006;137:661-664

6. Raptis NV, Michalakis KX, Hirayama H. Optical behavior of current ceramic systems. Int J Periodontics Restorative Dent 2006;26:31-41.

7. Dozić A, Kleverlaan CJ, Meegdes M, van der Zel J, Feilzer AJ. The influence of porcelain layer thickness on the final shade of ceramic restorations. J Prosthet Dent 2003;90:563-570.

8. Heffernan MJ, Aquilino SA, Diaz-Arnold AM, Haselton DR, Stanford $\mathrm{CM}$, Vargas MA. Relative translucency of six all-ceramic systems. Part II: core and veneer materials. J Prosthet Dent 2002;88:10-15.

9. Johnston WM, Ma T, Kienle BH. Translucency parameter of colorants for maxillofacial prostheses. Int J Prosthodont 1995;8:79-86.

10. Kaizer MR, Diesel PG, Mallmann A, Jacques LB. Ageing of silorane-based and methacrylate-based composite resins: effects on translucency. J Dent 2012;40:64-71.

11. Yu B, Lee YK. Influence of color parameters of resin composites on their translucency. Dent Mater 2008;24:1236-1242.

12. Ruyter IE, Nilner K, Moller B. Color stability of dental composite resin materials for crown and bridge veneers. Dent Mater 1987;3:246-251.

13. Shokry TE, Shen C, Elhosary MM, Elkhodary AM. Effect of core and veneer thicknesses on the color parameters of two all-ceramic systems. J Prosthet Dent 2006;95:124-129.

14. O'Brien WJ, Kay KS, Boenke KM, Groh CL. Sources of color variation on firing porcelain. Dent Mater 1991;7:170-173.

15. Hajtó J, Marinescu C. An esthetic challenge: isolated areas of high translucency in laminate veneers. Eur J Esthet Dent 2012;7:282-294.

16. Chu FC, Chow TW, Chai J. Contrast ratios and masking ability of three types of ceramic veneers. J Prosthet Dent 2007;98:359-364.

17. Kamishima N, Ikeda T, Sano H. Color and translucency of resin composites for layering techniques. Dent Mater J 2005;24:428-432.

18. Vichi A, Ferrari M, Davidson CL. Influence of ceramic and cement thickness on the masking of various types of opaque posts. J Prosthet Dent 2000;83:412-417.

19. Son HJ, Kim WC, Jun SH, Kim YS, Ju SW, Ahn JS. Influence of dentin porcelain thickness on layered all-ceramic restoration color. J Dent 2010:38:71-77

20. de Azevedo Cubas GB, Camacho GB, Demarco FF, Pereira-Cenci T. The effect of luting agents and ceramic thickness on the color variation of different ceramics against a chromatic background. Eur J Dent 2011;5:245-252.

21. Bagis B, Turgut S. Optical properties of current ceramics systems for laminate veneers. J Dent 2013;41:24-30.

22. Shono NN, Al Nahedh HN. Contrast ratio and masking ability of three ceramic veneering materials. Oper Dent 2012;37:406-416.

23. Deany IL. Recent advances in ceramics for dentistry. Crit Rev Oral Biol Med 1996;7:134-143.

24. Nogueira $A D$, Della Bona $A$. The effect of a coupling medium on color and translucency of CAD-CAM ceramics. J Dent 2013;41:18-23.

25. Colorimetry CIE pub no 15.3. Vienna, Austria: CIE Central Bureau; 2004 